\title{
Um olhar sobre a residência estreita: Azuma House, casa manifesto e referência para a discussão
}

\section{Una mirada sobre la residencia estrecha: Azuma House, casa manifiesta y referencia para la discusión}

\author{
DOI: 10.17981/mod.arq.cuc.19.1.2017.03
}

Artículo. Fecha de recepción: 10/05/2017 Fecha de aceptación: 11/09/2017

\author{
Felipe Porfiro de Oliveira \\ Pontifícia Universidade Católica do Rio Grande do Sul. \\ f.porfiro@gmail.comf \\ Roberta Krahe Edelweiss \\ Universidade do Vale do Rio dos Sinos, São Leopoldo (UNISINOS) \\ robertaedelweiss@gmail.com
}

Para citar este artículo:

Porfiro, F. y Krahe, R. (2017). Um olhar sobre a residência estreita: Azuma House, casa manifesto e referência para a discussão. MODULO ARQUITECTURA-CUC, vol. 19, no. 1, pp. 57-68. DOI: 10.17981/mod.arq.cuc.19.1.2017.03

\section{Resumo}

No início do século XX surge a tipologia da casa operária residências estreitas lado a lado que configuram a habitação do trabalhador em zonas centrais da cidade. Com a falta de oportunidade para novas construções de casas nos centros urbanos, voltam-se os olhares para a tipologia da casa operária estreita e a possibilidade de requalificação junto ao cenário da residência contemporânea. Mas a re-arquitetura desse tipo de residência implica estudar estratégias atuais de projeto que permitam trazer medidas qualitativas à nova edificação. Para tanto, o artigo, a partir do exemplo da Azuma House, analisa esses aspectos do projeto em relação à suas diretrizes, conceito, programa, organização espacial e manifesto.

Palavras-chave: casa estreita, edificação estreita, casa manifesto, Azuma House, Tadao Ando.

\section{Resúmen}

A inicios del siglo XX surge la tipología de las "casas operárias", casas estrechas lado a lado que configuran la habitación del trabajador en zonas centrales de la ciudad. Con poca oportunidad para las nuevas construcciones de casas en los centros urbanos, la tipología de la "casa operária" estrecha para a tener especial atención por su posibilidad de recualificación junto al escenario de la casa contemporánea. La re-arquitectura de ese tipo de casa inspira estudiar las estrategias actuales de proyecto que permiten traer medidas cualitativas a la nueva edificación. Para tanto, el artículo, a partir del ejemplo de la Azuma House, analiza los aspectos del proyecto cuanto a sus directrices, concepto, programa, organización espacial y manifiesto.

Palabras clave: casa estrecha, edificación estrecha, casa manifiesto, Azuma House, Tadao Ando. 


\section{INTRODUÇÃO}

Com o crescimento demográfico e o avanço da procura por habitação nas principais cidades do mundo, como Nova Iorque, Tóquio, São Paulo e Amsterdam, surge naturalmente uma valorização do valor do solo pelo crescimento de edificações proposto pelo mercado imobiliário. Pertencer a esses centros, exige um grande aporte financeiro tanto de construtoras que exercem o papel de construção, quanto da população que irá habitar esses prédios.

Lefebvre (2001) estabelece a relação entre valor de uso e valor de troca no território urbano. É na cidade da especulação imobiliária e do capital que se observam grandes diferenças no valor do território. A habitação unifamiliar, interesse específico do presente artigo, apresenta grande valor social para a população. E a arquitetura, como ferramenta de transformação, busca soluções para problemáticas encontradas pela sociedade, estas sendo alternativas aos projetos usuais de casas localizadas nos principais centros urbanos onde é cada vez mais visível a escassez de lotes disponíveis para novas construções.

Podemos observar no período da $1^{a}$ Revolução Industrial, através do êxodo rural o aumento demográfico urbano incentivado por melhores condições de vida. No entanto, as dificuldades impostas pelo alto custo de moradia reflete-se no surgimento de cortiços, favelas e a necessidade de investimento em transporte e saneamento para garantir o mínimo de condições a esses trabalhadores. No mesmo período, em áreas centrais, surge a casa operária, normalmente situada junto de outras residências de mesmas características, formando assim um conjunto residencial que traz a classe operária para perto do trabalho. Quanto suas características, a que mais chama atenção é o maior aproveitamento do lote para a inserção do maior número de residências nele, assim criando casas com dimensões mínimas de fachada frontal, até quatro metros, e grande amplitude no seu comprimento, consequência da locação no terreno.

No século XXI os olhares voltam-se novamente aos conjuntos de casas operárias. $O$ interesse em modernizar essa tipologia surge como resposta as alternativas de residir em casas nas áreas centrais. A casa operária do início do século $X X$, que possuia programas específicos para a família da classe trabalhadora não atende mais às necessidades da família contemporânea e seus costumes. É necessário repensar a tipologia da casa estreita e buscar referências projetuais que solucionam os problemas encontrados na residência de lote estreito e que atendam as premissas da contemporaneidade.

González (2017) a partir de 22 exemplos de habitações estreitas relaciona as habitações estreitas com uma "pegada estreita" e um "amplo impacto". Friedman (2010), por sua vez, relaciona as habitações estreitas com o "design eficiente". 
A partir do entendimento observa-se, a vinculação das casas estreitas ao desempenho do programa de necessidades relacionado às práticas de projeto e suas soluções aplicadas.

Mas como é possível, a partir do projeto arquitetônico, requalificar a tipologia da casa estreita que foi pensada para outro tipo de família em outra época, sendo que as dimensões da fachada frontal junto da situação entre medianeiras dificulta relações com agentes externos utilizadas em projetos convencionais?

\section{A habitação estreita: estudo de caso Azuma House}

Conforme supracitado, o conjunto de casas operárias tornou-se uma alternativa de residência no século XXI, porém com completas alterações no projeto original para atender os novos moradores. O entendimento das diretrizes de projeto destas novas casas estreitas, com limitante de até $4 \mathrm{~m}$ de fachada frontal, entre medianeiras são a preocupação do presente artigo. É a partir do exemplo da Azuma House do arquiteto Tadao Ando, por ser uma casa manifesto que através de exageros das relações sensoriais da edificação com os agentes naturais externos, que buscamos observar estratégias projetuais adotadas em função da relação entre programa habitacional e a residência estreita.
Furuyama (1997) categoriza a Azuma House como uma obra monística, pois apresenta formas puras, contornos nítidos e espaço forte, características marcantes no início da sua carreira. Furuyama (1997)ainda aponta que a casa manifesto de Ando, nos exemplifica as reais intenções quanto a experiência que a sua arquitetura pode proporcionar. Sua fase monística entrega a simplicidade das formas e principalmente dos materiais, criando assim uma homogeneidade da materialidade na casa. A maneira com que lida através do desafio da concepção da Azuma House, num lote que apresenta condicionantes de restrição, junto da habilidade projetual de obter resultados que relacionam arquitetura e natureza e a ação desses fatores do tempo na residência, nos guiam para as respostas projetuais que observamos em casas estreitas do século XXI.

\section{[...] Ando coloca vários elementos em confronto -forma versus forma, forma versus espaço, interior versus exterior e natureza versus geometria- e o conflito resultante decide a composição de sua arquitetura. (Furuyama,1997)}

Podemos observar, através do projeto Azuma House (Fig. 1) de autoria do arquiteto japonês Tadao Ando, no ano de 1976, a inserção de uma residência em um terreno de 3,3 metros de frente e comprimento de 14,10 metros numa quadra tradicional do centro de Osaka, Japão. 


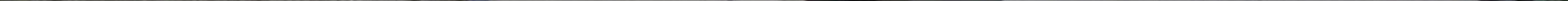


Seguindo a tendência de reapropriação de casas antigas para inserção de novas edificações, a Azuma House é resultado da substituição de uma de três casas geminadas anteriores à guerra num quarteirão residencial central. A casa manifesto possui diversos aspectos únicos que instigam o pensamento sobre suas diretrizes de projeto. O conceito da edificação vai além de uma residência tradicional, onde materiais típicos da arquitetura japonesa e padrões repetidos, como a utilização de madeira e a falta de privacidade entre os moradores da quadra pela exagerada proximidade das edificações são encontradas. Ela se caracteriza por ser uma crítica ao conforto no residir que o ser humano foi buscando com sua evolução e o afastamento de aspectos naturais, consequentes da utilização de elementos tecnológicos que equilibram o ambiente. A Azuma House busca no seu conceito a coexistência com a natureza como sendo fundamental para a existência humana.

Ao primeiro olhar, a falta de vitalidade decorrente do uso do concreto como material principal na composição da casa sugere a falta da natureza. Mas podemos observar que a ligação com o aspecto natural está relacionado pelos fenômenos físicos como a iluminação proveniente do sol, a chuva e a ventilação central, diferente da ventilação cruzada buscada em muitos projetos residenciais contemporâneos.

4 Fig. 2. Row House (Azuma House), Sumiyoshi, Osaka, in Japan, 1976. Fonte: http://www.architravel.com/architravel/ building/row-house-azuma-house/ 
A Azuma House apresenta conceitos fortes sobre o morar, mas mesmo se tratando de uma casa manifesto que possui uma mensagem a ser transmitida, ela também chama atenção por escoIhas singulares como a construção no lote estreito e pelas alternativas que estão presentes no projeto e que se assemelham às residências contemporâneas conforme o presente artigo irá analisar.

As decisões de projeto, neste exemplo, buscam a valorização de espaços através de recursos como a iluminação natural para todos os cômodos e a amplitude visual dos ambientes.

\section{A Quadra}

Localizado em uma zona central de Osaka, Japão, a residência se destaca por quebrar o parâmetro de casa encontrada na rua. A linguagem da quadra é confusa em função da mistura do uso residencial com comercial e de um espaço para estacionamento dos carros dos moradores. Conforme podemos observar no Diagrama de Quadra (Fig. 4), um dos fatores que agravam na sensação da falta de identidade de cada edificação é a proximidade das mesmas, que não apresentam recuos em relação ao terreno.

\section{2}

Fig. 3. Imagem de satélite de Sumiyoshi, Osaka, Japão.

Fonte: () Google Earth

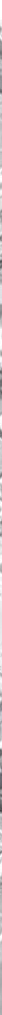




\section{Fachadas}

Conforme o conceito proposto pelo arquiteto, sua intenção na concepção das fachadas foi proporcionar que o morador se exclua do contexto urbano e se aproprie das sensações ocasionadas pela ação da natureza dentro da casa. A fachada frontal possui apenas a porta de acesso principal.
Podemos observar logo na fachada uma decisão de projeto nada comum para uma situação de casa estreita. Tadao Ando opta por não utilizar a face da edificação que poderia gerar uma quantidade significativa de entrada de luz e ventilação cruzada, para quebrar a falta de identidade da rua.

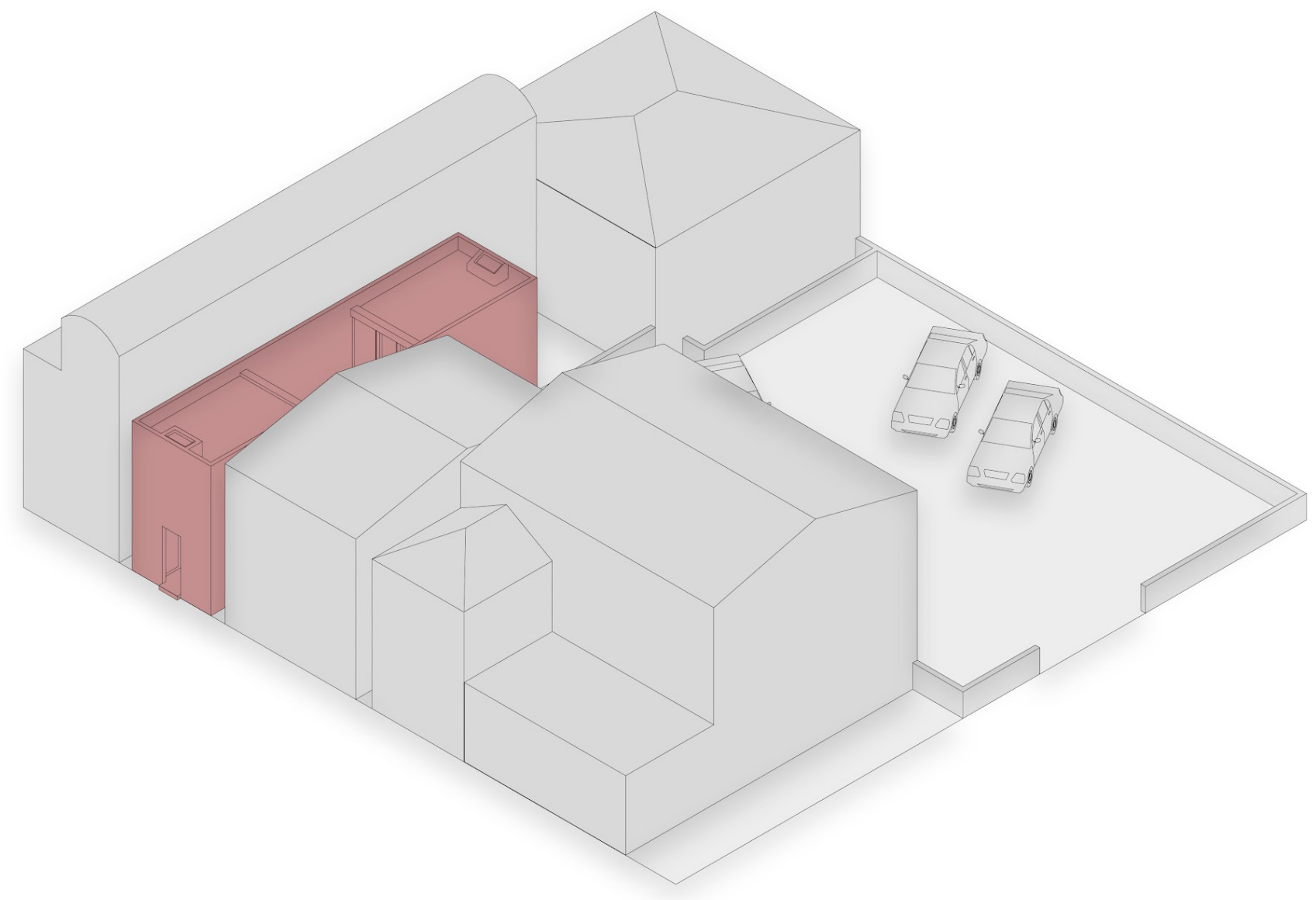

Fig. 4. Diagrama de Quadra Row House

(Azuma House), Sumiyoshi, Osaka, in Japan, 1976. 
A partir da decisão de utilizar recuos laterais estreitos, o projeto proporciona a possibilidade de uso de esquadrias com vidros fixos para entrada de luz em todos os cômodos.

Conforme Diagrama de Fachadas (Fig. 5), podemos observar a utilização de esquadrias com vidros fixos, seguindo uma repetição simétrica, para a iluminação lateral da edificação. O arquiteto utiliza a iluminação zenital nas lajes superiores para permitir a entrada de luz nos dormitórios.

\section{O Programa}

O programa divide-se claramente em três módulos e dois pavimentos. Juntamente ao acesso principal, localiza-se no primeiro módulo do térreo a sala de estar. O segundo módulo é reservado para o pátio interno que possui a função de iluminação, ventilação e circulação do primeiro

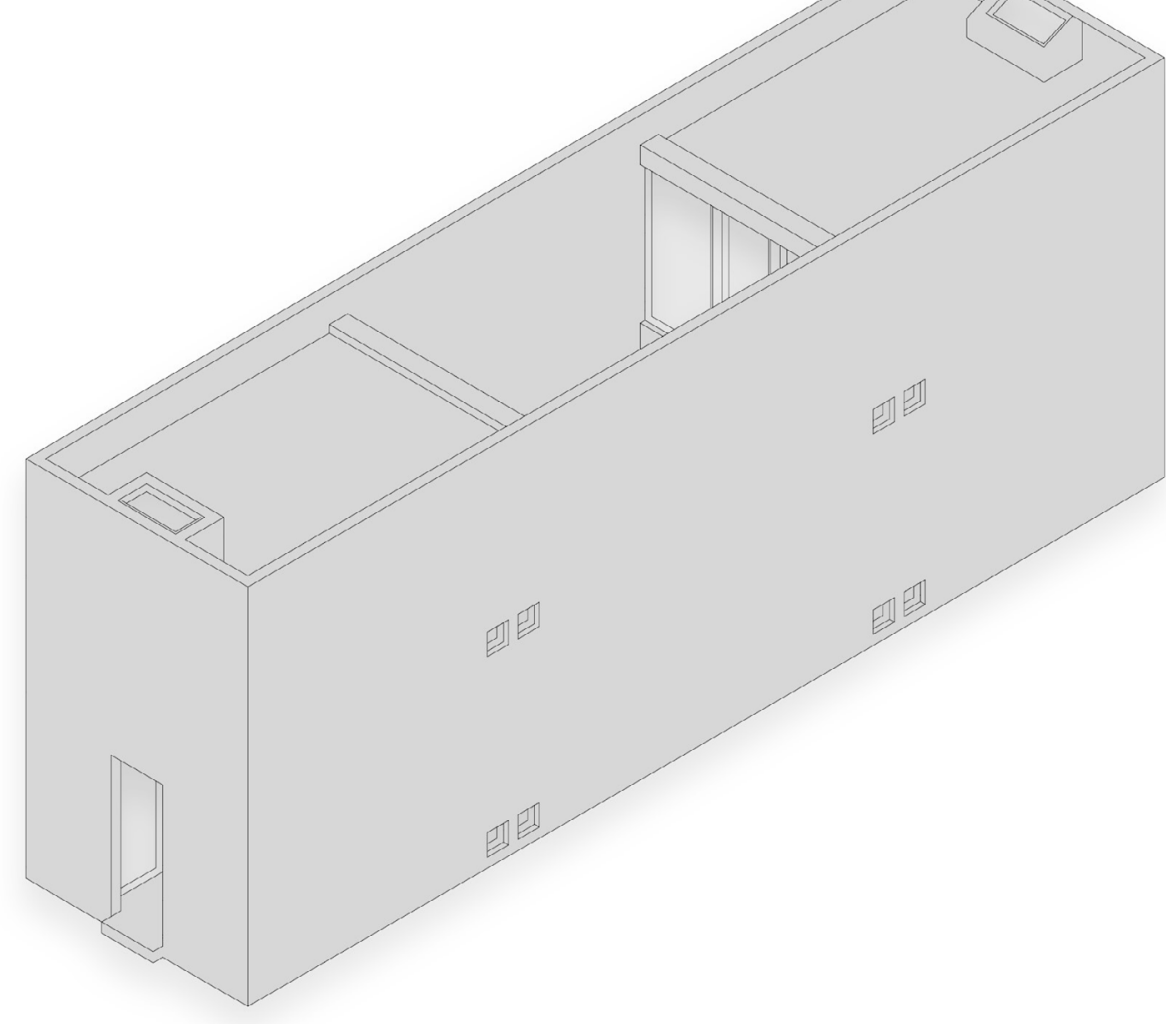

Fig. 5. Diagrama de Fachadas Row House

(Azuma House), Sumiyoshi, Osaka, in Japan, 1976. 
ao terceiro módulo térreo onde possui a área de cozinha e banho. No segundo pavimento pela escada localizada no centro, ainda estaremos no segundo módulo onde possui uma passarela que permite acesso aos demais onde estarão os quartos. Podemos observar que apesar do terreno estreito, a decisão de colocar um pátio central, permite a integração e amplitude dos ambientes ao permitir a entrada de iluminação. Podemos observar que apesar da falta de janelas na fachada frontal, Tadao Ando soluciona a entrada de luz através de aberturas zenitais e laterais.

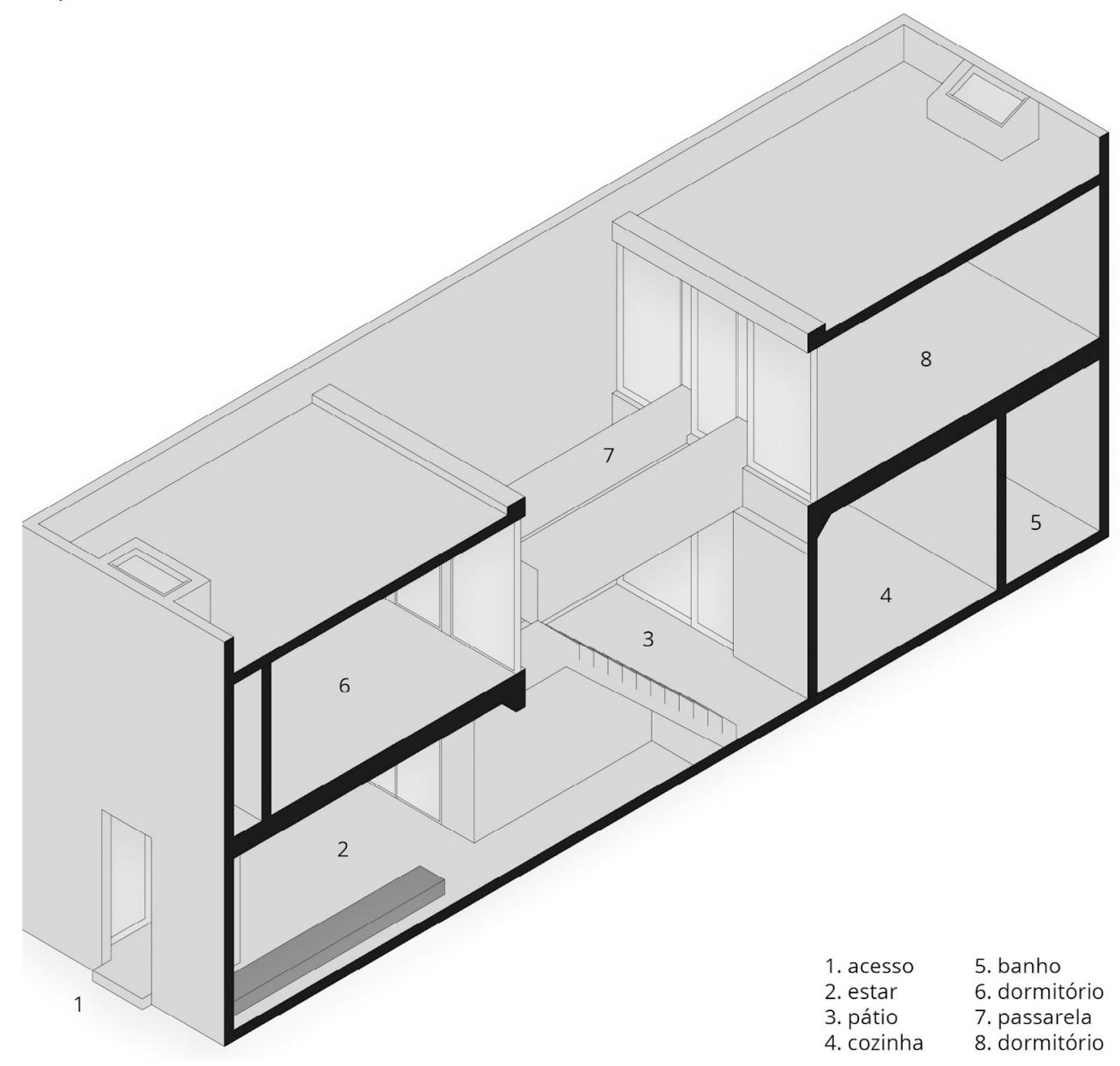

Fig. 6. Diagrama Corte Perspectivado Row House (Azuma House), Sumiyoshi, Osaka, in Japan, 1976. 


\section{A Circulação}

A principal circulação da Azuma House ocorre através do pátio central. Além de possuir a função de ventilação e iluminação, no pátio há a escada que dá acesso ao segundo pavimento e a passarela que distribui o fluxo entre os dormitórios. No primeiro pavimento a passarela possui a função de marquise para proteger quem percorre

o caminho entre a sala de estar para a cozinha e banheiro das ações naturais do tempo.

Apesar do fluxo da casa parecer simples, além de possuir o papel de distribuição entre os ambientes, ele permite ao morador interagir com os fenômenos naturais que estão concentrados no pátio principal.

Fig. 7. Corte Row House (Azuma House), Sumiyoshi, Osaka, in Japan, 1976.

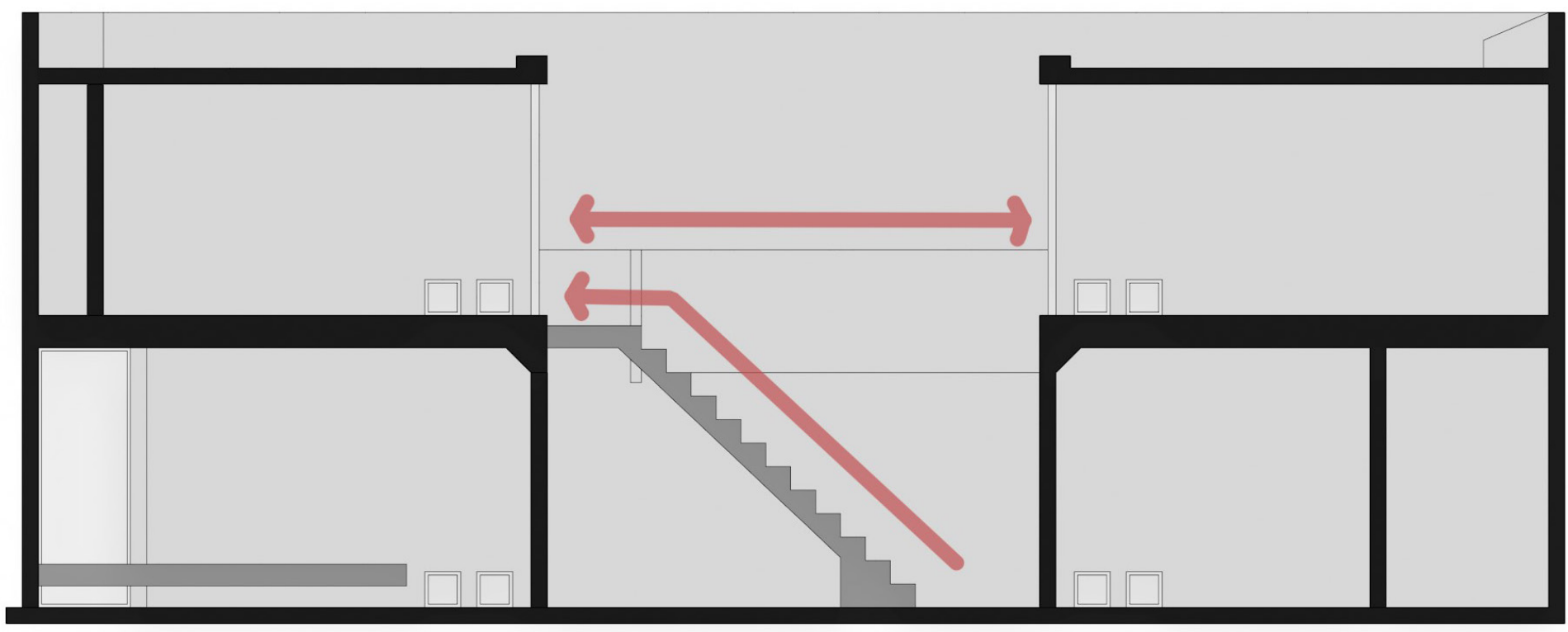




\section{A materialidade}

Tadao Ando opta por utilizar o concreto como material principal na residência. Além de desempenhar o papel estrutural como realiza na maioria das vezes quando empregado em toda edificação, na Azuma House o concreto possui funções diretamente ligadas ao conceito da casa. Por se tratar de um material frio, de cores neutras, quando sofre ações da natureza acaba por gerar um efeito intimista no usuário. Os demais materiais que compõem a residência são a pedra ardósia e o vidro. Esse último tendo o papel de permitir a entrada de luz nos ambientes.

\section{Conclusão}

A intenção de extrair da Azuma House as relações de intensidade entre forma, materialidade e fatores climáticos, nos permite analisar como Ando utilizou diretrizes organizacionais de setores, aberturas e transparências para despertar as emoções na sua arquitetura. Por mais que a Azuma House é considera manifesto, as relações provenientes dessa experimentação é que podem ser replicadas de maneira controlada na residência estreita contemporânea.
Ando exagera ao induzir o contato de chuva e vento ao transitar entre o pátio central e os dois módulos da residência, sendo que para acessar o banheiro é necessário percorrer esse trajeto. Mas podemos observar que ao centralizar o pátio, ele cria nesse setor a função de pulmão da casa. O pátio permite a circulação de ar e iluminação natural para todos os cômodos que estão voltados internamente. Logo o problema de ventilação natural que uma casa estreita entre medianeiras apresenta num primeiro olhar acaba por ser resolvida, além de criar relações entre os três diferentes setores.

A casa estreita, como no exemplo da Azuma House gera exemplos a serem referenciados em edificações de mesmas características.

Esta relação entre casa estreita e estratégias projetuais, apresenta-se como uma nova possibilidade de readequação arquitetônica às casas operárias resultantes de transformações urbanas no início do século XX que apresentam dimensões reduzidas em relação ao padrão do bairro ou loteamento, assim trazendo para o cenário atual as alternativas já utilizadas para contornar o problema da moradia, mas requalificado para o usuário contemporâneo. 


\section{REFERÊNCIAS}

Friedman, A. (2010). Narrow Houses: new directions in efficient design. Londres: Princeton Architectural Press.

González, M. F. (2017). 22 Skinny Houses with a Narrow Footprint and a Broad Impact. Disponível em <https://www. archdaily.com/869475/22-skinny-houses-with-a-narrow-footprint-and-a-broad-impact> Acesso em abril de 2018
Lefebvre, H. (2001). O direito à cidade. São Paulo: Editora Centauro.

Furuyama, M. (1997). Tadao Ando. São Paulo: Editora Martins Fontes. 